\title{
PENGARUH WAKTU ELECTROPLATING TERHADAP LAJU KOROSI DAN KEKUATAN TARIK PADA PELAPISAN BAJA KARBON RENDAH DENGAN HARDCHROME
}

\author{
Aziz Khoiril Anwar*, S. M. Bondan Respati, Agung Nugroho \\ Jurusan Teknik Mesin, Fakultas Teknik, Universitas Wahid Hasyim \\ Jl. Menoreh Tengah X/22, Sampangan, Semarang 50236, Indonesia \\ "Email: azizkhoiril17@gmail.com
}

\begin{abstract}
Abstrak
Baja ST 40 merupakan salah satu jenis baja karbon rendah, dengan kandungan karbon (C) kurang dari $0,3 \%$ C. Secara umum baja karbon rendah mempunyai beberapa kelebihan yaitu mempunyai sifat tangguh, ulet serta harganya relatif murah. Namun, baja karbon rendah juga memiliki beberapa kelemahan diantaranya laju korosi yang tinggi. Salah satu cara untuk meningkatkan ketahanan terhadap korosi pada baja adalah electroplating hardchrome. Tujuan dari penelitian ini yaitu untuk mengetahui pengaruh waktu electroplating terhadap laju korosi dan kekuatan tarik pada pelapisan baja karbon rendah dengan hardchrome. Proses electroplating hardchrome menggunakan variasi waktu proses 5 menit, 10 meni, 15 menit dan 20 menit dengan kerapatan arus 25 A/dm2 dan tegangan 6,5 volt. Pengujian laju korosi menggunakan metode kehilangan berat dengan media korosi larutan NaCl konsentrasi $3 \%$ dan pengujian tarik menggunakan alat uji tarik dengan standar ASTM D 638 tipe II untuk mengetahui nilai kekuatan tariknya. Hasil pengujian menunjukkan bahwa lapisan yang terbentuk pada proses electroplating hardchrome sangat dipengaruhi waktu proses pencelupan. Ketebalan lapisan mengalami kenaikan dengan meningkatnya waktu pencelupan electroplating hardchrome, dimana ketebalan lapisan tertinggi pada waktu 20 menit yaitu 233,3 $\mu \mathrm{m}$. Nilai laju korosi mengalami penurunan dengan meningkatnya waktu pencelupan electroplating hardchrome, dimana laju korosi terendah pada waktu 20 menit yaitu 0,19 $\mathrm{mm} / \mathrm{th}$. Nilai kekuatan tarik mengalami penurunan karena material menjadi getas saat proses pencelupan, tetapi semakin lama proses waktu pencelupan electroplating hardchrome yang dilakukan maka kekuatan tarik akan semakin tinggi karena mengalami pertambahan ketebalan setiap variasi waktu, dimana kekuatan tarik tanpa adanya pelapisan yaitu 784,574 Mpa sedangkan kekuatan tarik tertinggi dengan adanya pelapisan pada waktu pencelupan selama 20 menit electroplating hardchrome yaitu 709,089 Mpa.
\end{abstract}

Kata kunci: electroplating hardchrome, waktu, laju korosi, kekuatan tarik

\section{PENDAHULUAN}

Penggunaan logam di era perkembangan teknologi dan industri sebagai salah satu material penunjang sangat besar peranannya, akan tetapi dalam kehidupan sehari-hari banyak faktor yang menyebabkan daya guna logam tersebut menurun. Salah satu penyebab faktor itu adalah terjadinya korosi pada logam. Pengujian laju korosi yang telah berkembang sedemikian jauhnya sehingga bisa dilakukan dengan berbagai metode. Metode celup bisa dimanfaatkan untuk menentukan nilai kehilangan berat.

Baja karbon rendah memiliki kandungan karbon kurang dari $0,3 \%$. Jenis baja ini sering dipakai juga untuk konstruksi-konstruksi mesin yang saling bergesekan seperti kawat, paku, bodi mobil, knalpot, pipa-pipa saluran, roda gigi, poros, dan lain-lain karena sangat ulet (Amanto dan Daryanto, 1999). Namun kekerasan permukaan dari baja tersebut tergolong rendah, maka perlu di modifikasi atau memperbaiki sifat kekerasan pada permukaannya.

Proses electroplating merupakan salah satu metode dari pelapisan logam. Proses pelapisan electropating sering disebut juga dengan elektrodeposisi, yaitu suatu proses pengendapan/deposisi logam pelindung di atas logam lain dengan cara elektrolisasi. Proses pelapisan ini bertujuan untuk mendapatkan sifat khusus permukaan seperti sifat tahan terhadap korosi, sifat keras, sifat tahan aus, sifat tahan terhadap suhu yang tinggi dan menambah keindahan tampak luar suatu benda atau gabungan dari beberapa tujuan di atas secara bersama-sama, misalnya dengan melapisi saluran gas buang kendaraan dengan hardchrome dapat meningkatkan ketahanan terhadap korosi. Selain tegangan dan komposisi 
larutan, pengaruh waktu pencelupan juga sangat mempengaruhi proses electroplating (Purwanto dan Syamsul, 2005).

Dalam penelitian Darmawan, dkk. (2015) tentang pengaruh variasi kuat arus listrik dan waktu proses electroplating terhadap kekuatan tarik, kekerasan dan ketebalan lapisan pada baja karbon rendah dengan krom. Penelitian ini menggunakan baja karbon rendah yang dilapisi dengan metode electroplating dengan variasi kuat arus listrik 17,8 A; 22,7 A dan 27,3 A, serta waktu pemrosesan 5, 10, dan 15 menit.

Ketebalan lapisan krom meningkat seiring dengan meningkatnya kuat arus dan lamanya waktu lapisan. Nilai tertinggi dari ketebalan lapisan krom dengan kuat terjadi pada 27,3 A dan waktu 15 menit pengamatan mikroskop bernilai 0,483 di mana terdapat perbedaan antara perhitungan dan pengamatan mikroskop, pembesaran berkisar 400 kali dari 99,9\%. Nilai kekerasan tertinggi diperoleh dengan kuat arus 27,3 A dan waktu 15 menit bernilai 23,58 VHN atau $12,621 \%$. Untuk uji tarik sendiri kekuatan tarik dengan nilai tertinggi $627,8 \quad \mathrm{~N} / \mathrm{mm}^{2}$ dengan regangan $6,65 \%$.

Dalam penelitian Sutrisno (2012) tentang variasi waktu hard chromium plating terhadap karakteristik struktur mikro, nilai kekerasan dan laju korosi baja karbon rendah. Proses hard chromium plating menggunakan variasi waktu proses 20 menit, 40 menit dan juga 60 menit dengan kuat arus proses sebesar $10 \mathrm{~A}$. Pengujian korosi menggunakan alat uji laju korosi tipe sel tiga elektroda dengan potensiostat tipe PGS-201T dengan media korosi $0,5 \%$ larutan $\mathrm{NaCl}$.

Hasil pengujian menunjukkan bahwa lapisan yang terbentuk pada proses hard chromium plating sangat dipengaruhi waktu proses pelapisan. Nilai kekerasan akan meningkat seiring dengan meningkatnya waktu proses. Nilai kekerasan yang paling tinggi terjadi pada proses hard chromium plating dengan kuat arus waktu 60 menit yaitu 562 VHN. Nilai laju korosi mengalami penurunan dengan meningkatnya waktu proses, dimana laju korosi terendah pada waktu 60 menit yaitu $0,989 \mathrm{~mm} /$ year.

\section{METODOLOGI}

Penelitian ini dilakukan menggunakan mesin electroplating. Laju korosi diuji dengan metode celup diam dan metode celup berputar/mengalir. Kemudian untuk mengetahui struktur mikro dari spesimen uji digunakan foto makro/mikro dengan tipe Mikroskop Metalografi Tipe XSZ-107 BN. Untuk mengetahui kekuatan tarik spesimen Alat uji tarik dengan standar ASTM D 638 tipe II, uji.

Bahan yang digunakan dalam penelitian ini adalah berupa bahan kimia untuk pembuatan larutan elektrolit yang dipakai beserta takarannya mengacu pada penelitian dari Priyono (2018) dapat dilihat pada Tabel 1.

Tabel 1 Formulasi larutan electroplating hardchrome

\begin{tabular}{cll}
\hline No & Nama bahan kimia & Takaran \\
\hline 1 & Katalis & $15 \mathrm{gr} / \mathrm{l}$ \\
2 & Asam sulfat & $0,87 \mathrm{gr} / \mathrm{l}$ \\
3 & Asam kromat & $150 \mathrm{gr} / 1$ \\
\hline
\end{tabular}

Tabel 2 Bahan pelengkap electroplating hardchrome

\begin{tabular}{|c|c|c|}
\hline No & Nama & Kegunaannya \\
\hline 1 & Detergen & \begin{tabular}{ll} 
Untuk membersihkan & \multicolumn{2}{c}{} \\
sisa bensin pada \\
pembersih minyak
\end{tabular} \\
\hline 2 & Bensin & $\begin{array}{l}\text { Untuk menghilangkan } \\
\text { lapisan minyak }\end{array}$ \\
\hline 3 & Air & $\begin{array}{l}\text { Untuk pembilasan pada } \\
\text { tahap selesai pencelupan }\end{array}$ \\
\hline 4 & $\mathrm{H}_{2} \mathrm{SO}_{4}$ & $\begin{array}{l}\text { Sebagai aktifasi benda } \\
\text { kerja }\end{array}$ \\
\hline
\end{tabular}

Material baja karbon rendah (ST 40) dalam bentuk silinder seperti terlihat pada gambar 1 . Sedangkan Larutan Aquades dan $\mathrm{NaCl}$ dengan konsentrasi 3\%, digunakan untuk media pengujjian laju korosi.

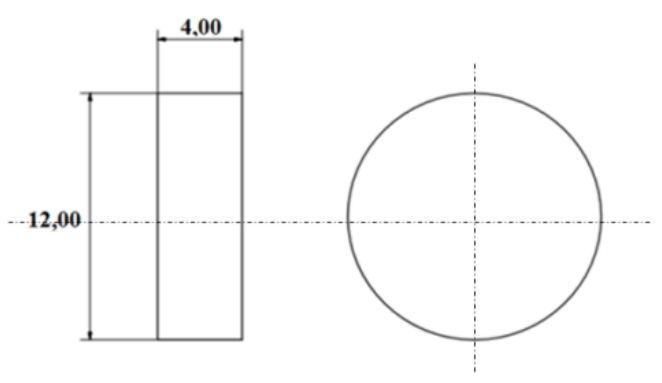
Gambar 1 Ukuran spesimen uji korosi
dalam satuan milimeter (mm) 


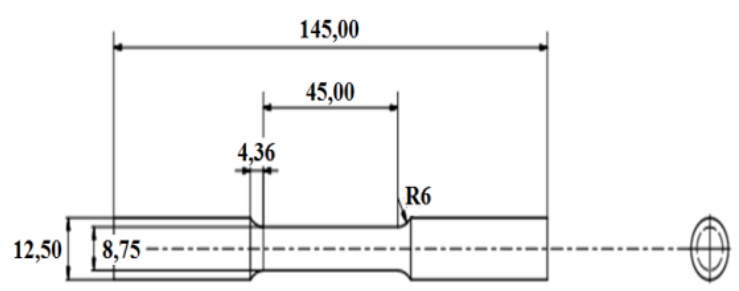

Gambar 2 Ukuran spesimen uji tarik dalam satuan milimeter $(\mathbf{m m})$

\section{HASIL DAN PEMBAHASAN}

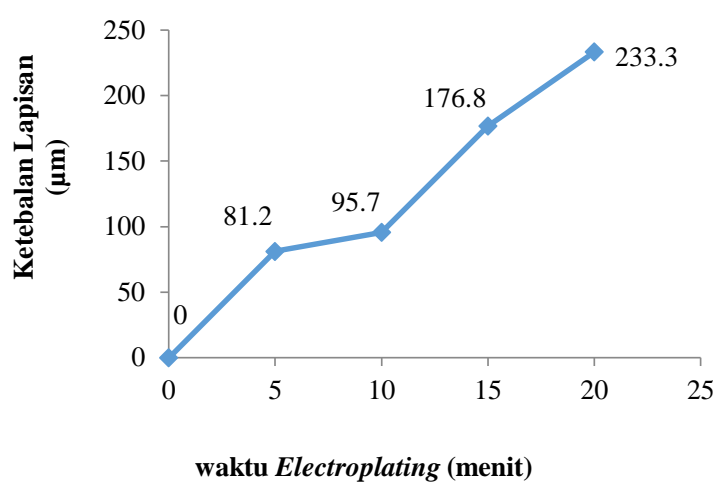

\section{Gambar 3 ketebalan lapisan hardchrome ST 40 dengan variasi waktu electroplating}

Gambar 3 menunjukkan bahwa material yang dilapisi hardchrome mengalami kenaikan ketebalan lapisannya. Ketebalan lapisan mengalami kenaikan setiap pertambahan variasi waktu 5 menit pencelupan electroplating hardchrome. Hal ini menunjukkan bahwa semakin lama proses waktu pencelupan electroplating hardchrome yang dilakukan maka ketebalan lapisan akan semakin tebal, sama halnya dengan penelitian menurut Darmawan, dkk. (2015) yang mengatakan bahwa ketebalan spesimen hasil proses electroplating semakin meningkat seiring bertambahnya waktu yang diberikan. Ketebalan lapisan terendah yaitu pada waktu pencelupan selama 5 menit electroplating hardchrome yang mempunyai nilai $81,2 \mu \mathrm{m}$. Ketebalan lapisan tertinggi yaitu pada waktu pencelupan selama 20 menit electroplating hardchrome yang mempunyai nilai $233,3 \mu \mathrm{m}$.

Waktu electroplating juga berpengaruh terhadap laju korosi Material yang dilapisi hardchrome mengalami penurunan laju korosi. Laju korosi mengalami penurunan setiap pertambahan variasi waktu 5 menit pencelupan electroplating hardchrome. Berdasarkan gambar 4 menunjukkan bahwa semakin lama proses waktu pencelupan electroplating hardchrome yang dilakukan maka laju korosi akan semakin rendah, sama halnya dengan penelitian menurut Sutrisno (2012) yang mengatakan bahwa laju korosi akan mengalami penurunan dengan adanya peningkatan waktu proses hard chromium plating.

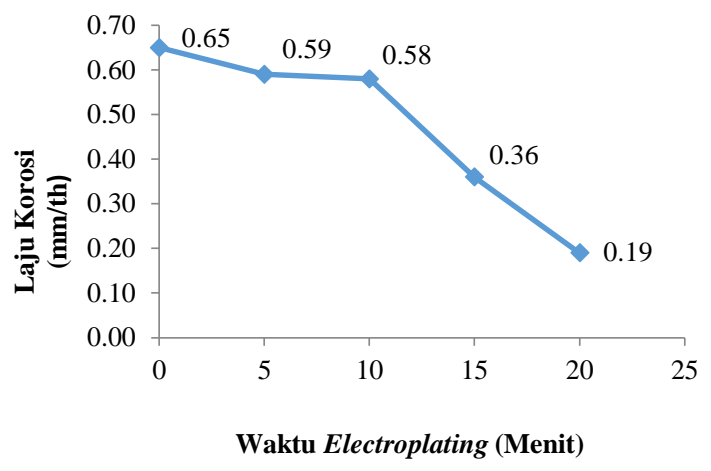

\section{Gambar 4 Grafik pengaruh waktu electroplating hardchrome terhadap laju korosi pada baja karbon rendah (ST 40)}

Laju korosi tanpa adanya pelapisan mempunyai nilai sebesar $0,65 \mathrm{~mm} / \mathrm{th}$. Laju korosi tertinggi yaitu pada waktu pencelupan selama 5 menit electroplating hardchrome mempunyai nilai $0,59 \mathrm{~mm} / \mathrm{th}$ sedangkan laju korosi terendah yaitu pada waktu pencelupan selama 20 menit electroplating hardchrome mempunyai nilai $0,19 \mathrm{~mm} / \mathrm{th}$.

Pelapisan hardchrome yang ditunjukkan pada Gambar 5 diketahui bahwa kekuatan tarik dari raw material ke material dengan pelapisan mengalami penurunan kekuatan yang di pengaruhi pada saat proses pencelupan electroplating hardchrome dilakukan karena disebabkan oleh bahan kimia yang sifatnya keras dan ter aliri listrik maka akan mempengaruhi keuletan spesimen sehingga mengalami getas, akan tetapi dengan pertambahan variasi waktu 5 menit pencelupan electroplating hardchrome kekuatan tarik mengalami kenaikan karena mengalami pertambahan ketebalannya.

Hal ini menunjukkan bahwa dengan adanya proses electroplating hardchrome kekuatan tarik akan mengalami penurunan karena material menjadi getas saat proses pencelupan, tetapi semakin lama proses waktu pencelupan electroplating hardchrome yang dilakukan maka kekuatan tarik akan semakin tinggi karena mengalami pertambahan ketebalan setiap variasi waktu. Kekuatan tarik 
tanpa adanya pelapisan mempunyai nilai sebesar 784,574 Mpa.

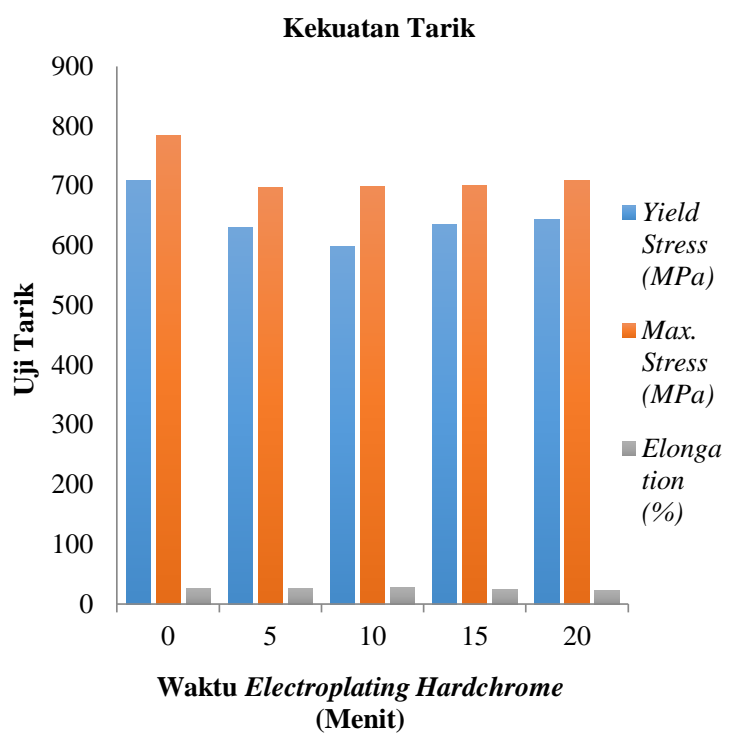

\section{Gambar 5 kekuatan tarik ST40 dengan variasi waktu electroplating}

Kekuatan tarik terendah yaitu pada waktu pencelupan selama 5 menit electroplating hardchrome mempunyai nilai sebesar 696,962 Mpa sedangkan kekuatan tarik tertinggi yaitu pada waktu pencelupan selama 20 menit electroplating hardchrome mempunyai nilai sebesar 709,089 Mpa.

\section{KESIMPULAN}

Berdasarkan analisa data dan pembahasan pada penelitian ini, maka dapat diambil

kesimpulan sebagai berikut:

1. Ketebalan lapisan mengalami kenaikan setiap pertambahan variasi waktu 5 menit pencelupan electroplating hardchrome. Hal ini menunjukkan bahwa semakin lama proses waktu pencelupan electroplating hardchrome yang dilakukan maka ketebalan lapisan akan semakin tebal. Ketebalan lapisan terendah yaitu pada waktu pencelupan selama 5 menit electroplating hardchrome yang mempunyai nilai $81,2 \mu \mathrm{m}$. Ketebalan lapisan tertinggi yaitu pada waktu pencelupan selama 20 menit electroplating hardchrome yang mempunyai nilai 233,3 $\mu \mathrm{m}$.

2. Laju korosi mengalami penurunan setiap pertambahan variasi waktu 5 menit pencelupan electroplating hardchrome. Hal ini menunjukkan bahwa semakin lama proses waktu pencelupan electroplating hardchrome yang dilakukan maka laju korosi akan semakin rendah. Laju korosi tertinggi yaitu pada waktu pencelupan selama 5 menit electroplating hardchrome mempunyai nilai $0,59 \mathrm{~mm} /$ th sedangkan laju korosi terendah yaitu pada waktu pencelupan selama 20 menit electroplating hardchrome mempunyai nilai $0,19 \mathrm{~mm} / \mathrm{th}$.

3. Kekuatan tarik mengalami penurunan kekuatan yang di pengaruhi saat proses pencelupan electroplating hardchrome, tetapi dengan pertambahan variasi waktu pencelupan electroplating hardchrome kekuatan tarik mengalami kenaikan. Hal ini menunjukkan bahwa dengan adanya proses electroplating hardchrome kekuatan tarik akan mengalami penurunan karena material menjadi getas yang dipengaruhi oleh cairan kimia keras dan ter aliri listrik, tetapi semakin lama proses waktu pencelupan electroplating hardchrome yang dilakukan maka kekuatan tarik akan semakin tinggi karena mengalami pertambahan ketebalan setiap variasi waktu. Kekuatan tarik terendah yaitu pada waktu pencelupan selama 5 menit electroplating hardchrome mempunyai nilai sebesar 696,962 Mpa sedangkan kekuatan tarik tertinggi yaitu pada waktu pencelupan selama 20 menit electroplating hardchrome mempunyai nilai sebesar 709,089 Mpa.

\section{SARAN}

Berdasarkan pada penelitian ini, maka dapat diambil saran sebagai berikut:

1. Dalam penelitian lebih lanjut, perlu dilakukan penambahan variasi waktu electroplating yang digunakan agar mendapatkan hasil yang terbaik.

2. Dalam penelitian lebih lanjut, perlu juga dilakukan penelitian pengaruh parameter lain seperti variasi konsentrasi larutan, arus dan jarak elektroda agar mendapatkan hasil electroplating yang terbaik.

3. Perlu dilakukan penelitian lebih lanjut tentang pengaruh waktu electroplating terhadap laju korosi dan kekuatan tarik pada baja karbon rendah dengan pelapisan hardchrome.

\section{DAFTAR PUSTAKA}

Amanto, H.-Daryanto, 1999, Ilmu Bahan, PT Bumi Aksara, Jakarta.

Darmawan D.P., A.S., Okariawan, I D.K. dan Sari, N.H., 2015, PengaruhaVariasi Kuat ArusaListrik danaWaktu Proses, jurnal penelitian Jurusan Teknik Mesin Fakultas 
Teknik Universitas Mataram, Mataram, Vol. 5, No. 2.

Priyono, S., 2018, Analisis KeausanaPIN-ONDISC Besi Cor dengan KekasaranaPermukaan Buatan dan Electroplating Hardchrome, Program Studi Teknik Mesin Fakultas Teknik Universitas Wahid Hasyim, Semarang.

Purwanto-Syamsul, H., 2005, Teknologi Industri Elektroplating, Badan Penerbit Universitas Dipenogoro, Semarang.

Sutrisno, 2012, variasi Waktu Hard Chromium Plating Terhadap Karakteristik Struktur Mikro, Nilai Kekerasan dan Laju Korosi Baja Karbon Rendah, Jurnal Program Studia Teknik Mesin Politeknika Surakarta. 